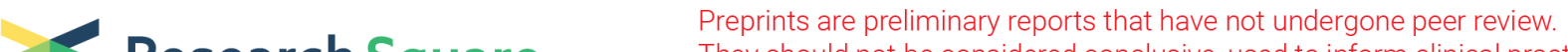 Research Square They should not be considered conclusive, used to inform clinical practice, or referenced by the media as validated information.
}

\section{Ecological succession of fungal and bacterial communities in Antarctic mosses affected by a fairy ring disease}

\author{
Luiz Henrique Rosa ( $\sim$ lhrosa@icb.ufmg.br) \\ Universidade Federal de Minas Gerais \\ Otávio Henrique Bezerra Pinto \\ Universidade de Brasília \\ Lívia Costa Coelho \\ Universidade Federal de Minas Gerais \\ Peter Convey \\ British Antarctic Survey, NERC \\ Micheline Carvalho-Silva \\ Universidade de Brasília

\section{Carlos Augusto Rosa} \\ Universidade Federal de Minas Gerais \\ Paulo EAS Câmara \\ Universidade de Brasília
}

\section{Research Article}

Keywords: Antarctica, climate change, environmental DNA, metabarcoding plant diseases

Posted Date: April 14th, 2021

DOI: https://doi.org/10.21203/rs.3.rs-393340/v1

License: (9) This work is licensed under a Creative Commons Attribution 4.0 International License. Read Full License 


\section{Abstract}

We evaluated fungal and bacterial diversity in an established moss carpet on King George Island, Antarctica, affected by 'fairy ring' disease using metabarcoding. These microbial communities were assessed through the main stages of the disease. A total of 127 fungal and 706 bacterial taxa were assigned. The phylum Ascomycota dominated the fungal assemblages, followed by Basidiomycota, Rozellomycota, Chytridiomycota, Mortierellomycota and Monoblepharomycota. The fungal community displayed high indices of diversity, richness and dominance, which increased from healthy through infected to dead moss samples. Bacterial diversity and richness were greatest in healthy moss and least within the infected fairy ring. Chalara sp. 1, Alpinaria sp., Helotiaceae sp. 2, Chaetothyriales sp. 1, Ascomycota sp. 1, Rozellomycota sp. and Fungi sp. were most abundant within the fairy ring samples. A range of fungal taxa were more abundant in dead rather than healthy or fairy ring moss samples. The dominant prokaryotic phyla were Actinobacteriota, Proteobacteria, Bacteroidota and Cyanobacteria. The taxon Cyanobacteriia sp., whilst consistently dominant, were less abundant in fairy ring samples. Microbacteriaceae sp. and Chloroflexi sp. were the most abundant taxa within the fairy rings. Our data confirmed the presence and abundance of a range of plant pathogenic fungi, supporting the hypothesis that the disease is linked with multiple fungal taxas. Further studies are required to characterise the interactions between plant pathogenic fungi and their host Antarctic mosses. Monitoring the dynamics of mutualist, phytopathogenic and decomposer microorganisms associated with moss carpets may provide bioindicators of moss health.

\section{Introduction}

Antarctic vegetation is dominated by bryophytes, with 116 species currently recognised representing cosmopolitan, endemic and bipolar taxa ${ }^{1,2}$. Antarctic mosses may form extensive carpets in some parts of Antarctica, particularly in the maritime Antarctic, contributing to the greatest development of 'fellfield' communities globally, and providing habitats and ameliorating Antarctica's extreme environmental conditions for contained microbial and invertebrate communities ${ }^{3,4,5}$ ). Well established Antarctic moss carpets may act as "sentinels" sensitive to environmental changes, particularly in temperature and hydration, across the Antarctic Peninsula region ${ }^{5}$. Moss carpet health has been a subject of research attention since the early years of Antarctic terrestrial research ${ }^{6}$. One of the most frequently reported concerns relating to moss health is that of attack by initially unidentified organism(s) resulting in the formation of a concentric ring ('fairy ring') visible on the surface of the carpet which eventually results

in the death of the moss $17,8,9,10,11,12,13$. Most recently, Rosa et al. ${ }^{14}$ recorded the development of fairy rings on previously unreported moss species from new locations in the western Antarctic Peninsula region, suggesting that the disease is more widespread in maritime Antarctica than previously believed and may be increasing in prevalence.

The majority of studies Antarctic moss fairy rings have considered that fungi are the cause of the disease. However, there is no consensus about which species is the phytopathogenic agent causing the disease. Fenton et al. ${ }^{11}$ was the first to propose Coleroa turfosorum, Bryosphaeria megaspora and Epibryon chorisodontii (Ascomycota), recovered from infected mosses on Signy Island, as the causative agent. Tojo et al. ${ }^{12}$ proposed Pythium polare (Oomycota) to be the species affecting Sanionia uncinata on King George Island. Pawłowska et al. ${ }^{13}$ recovered and proposed Psychronectria hyperantarctica as the phytopathogenic fungus causing fairy rings, in line with previous work by Putzke and Pereira ${ }^{15}$. Most recently, Rosa et al. ${ }^{14}$ reported that fairy rings host multiple fungal taxa, which might therefore act in consortium in causing the disease.

Despite the continent's typically extreme conditions, Antarctic fungi represent a diverse eukaryote microbial group, including symbionts, decomposers and opportunistic taxa, amongst which are phytopathogenic taxa ${ }^{16}$. Globally, approximately 300 species from 80 genera of Ascomycota are known to parasitize mosses or liverworts ${ }^{17}$. Earlier studies of the cause of fairy ring disease relied on culturing approaches and direct morphological identification. Rosa et al. ${ }^{14}$ was the first study to use molecular tools to identify fungi potentially involved. DNA metabarcoding using high throughput sequencing (HTS) is increasingly recognised as an important tool in investigating fungal diversity in various Antarctic ecosystems ${ }^{18,19,20}$. Therefore, in the present study, we evaluated fungal and bacterial diversity associated with different stages of the development of fairy ring disease in well established moss carpets on King George Island, South Shetland Islands, maritime Antarctic.

\section{Methods}




\section{Moss carpet sampling and identification}

Fungal and bacterial occurrence and diversity was investigated across different fairy ring disease stages in a well-established moss carpet on Keller Peninsula, King George Island, South Shetland Islands (maritime Antarctica; Fig. 1) during the austral summer of 2019/20. Three moss samples (each approximately $4 \mathrm{~cm}$ diameter) from each visible stage of the disease, defined as healthy, fairy ring (infected) and dead (Fig. 2), were obtained. The samples were immediately stored in sterilized whirl pack bags and frozen at $-20^{\circ} \mathrm{C}$ until further use. All sampled mosses were identified based on their macro- and micromorphological characteristics, using dissecting and optical microscopes with slides prepared using Hoyer's solution. The moss carpet was formed by the species Sanionia uncinata (Hedw.) Loeske identified by the Dr. Paulo EAS Câmara from University of Brasília based on macro- and micromorphological characteristics with reference to Ochyra et al. ${ }^{1}$. All moss specimens are deposited in the University of Brasília Herbarium (UB) under the code UB 210175. The licences to collect and study the plants in Antarctic Peninsula were authorized by the Secretariat of the Antarctic Treaty, Brazilian Antarctic Program and Ministry of Environment of Brazil, according to the international Antarctic Treaty rules. The study was conducted in accordance with relevant guidelines.

\section{DNA extraction, data analyses and fungal and bacterial identification}

Three samples of each of healthy, infected and dead mosses were processed separately to recover the total fungal and bacterial DNA. Total DNA was extracted using the QIAGEN DNeasy PowerLyzer PowerSoil Kit, following the manufacturer's instructions. Extracted DNA was used as template for generating PCR-amplicons. For fungi, the internal transcribed spacer 2 (ITS2) of the nuclear ribosomal DNA was used as a DNA barcode for molecular species identification ${ }^{21,22}$. PCR-amplicons were generated using the universal primers ITS3 and ITS4 for fungi ${ }^{23}$. For bacteria we used the $16 \mathrm{~S}$ rRNA gene V3-V4 region ${ }^{24,25}$. These amplicons were subjected to high throughput sequencing at Macrogen Inc. (South Korea) on an Illumina MiSeq sequencer ( $3 \times 300 \mathrm{bp})$, using the MiSeq Reagent Kit v3 (600-cycle) following the manufacturer's protocol.

Raw fastq files were filtered using BBDuk version 38.34 (BBMap - Bushnell B. - sourceforge.net/projects/bbmap/) to remove Illumina adapters, known Illumina artefacts, and the PhiX Control v3 Library. Quality read filtering was carried out using Sickle version 1.33 -q $30-150^{26}$, to trim 3' or $5^{\prime}$ ends with low Phred quality score, and sequences shorter than 50 bp were also discarded. The remaining sequences were imported to QIIME2 version 2019 for bioinformatics analyses ${ }^{27}$. For fungi, the qiime2-dada2 plugin is a complete pipeline that was used for filtering, dereplication, turn paired-end fastq files into merged and remove chimeras ${ }^{28}$. Taxonomic assignments were determined for amplicon sequence variants (ASVs) using the qiime2-feature-classifier ${ }^{29}$ classifysklearn against the UNITE fungal ITS database version $8.2^{30}$ trained with Naive Bayes classifier and a confidence threshold of 98.5\%. For bacteria, sequences were quality filtered using "quality-flter q-score-joined" plugin to improve diversity ${ }^{31}$. Sequences were denoised using deblur ${ }^{32}$ with-p-trim-length parameter of 300 , and were taxonomically assigned to sub-operational-taxonomic-units (sOTU) against the Silva 138 Ref NR 99 database pre-trained with Naive Bayes classifier using the "feature-classifier classifysklearn" plugin.

Many factors, including extraction, PCR and primer bias, can affect the number of reads obtained ${ }^{33}$, and thus lead to misinterpretation of absolute abundance ${ }^{34}$. However, Giner et $a{ }^{35}$ concluded that such biases did not affect the proportionality between reads and cell abundance, implying that more reads are linked with higher abundance ${ }^{36,37}$. Therefore, for comparative purposes, we used the number of reads as a proxy for relative abundance. Fungal classification followed Kirk et al. ${ }^{38}$, Tedersoo et al. ${ }^{39}$, MycoBank (http://www.mycobank.org), and the Index Fungorum (http://www.indexfungorum.org).

\section{Diversity, distribution and ecological analysis}

To quantify species diversity, richness and dominance, we used the following indices: (i) Fisher's a, (ii) Margalef's and (iii) Simpson's, respectively, to assess alpha diversity. In addition, the Sorensen and Bray-Curtis similarity indices were used to assess beta diversity among the fungal and bacterial assemblages present in the mosses representing the different disease stages. The relative abundance of the OTUs was used to quantify the taxa present in the different disease stages as described by Rosa et al. ${ }^{20}$, where OTUs with relative abundance $>10 \%$ were considered dominant, those with relative abundance of $1-10 \%$ intermediate and those with $<1 \%$ minor (rare) components of the microbial community. All of the results were obtained with $95 \%$ confidence and bootstrap values were calculated from 1,000 iterations. Taxon accumulation curves were obtained using the Mao Tao index. All 
diversity index calculations and t tests were performed using PAST, version $1.90^{40}$. To prepare Kronar charts, QIIME2 taxonomy classifications and the table of taxa abundance were converted to tsv and biom format, respectively. The table of fungal abundance was converted to tsv by using biom convert and combined with taxonomy classification with a custom script krona_qiime.py (https://github.com/lokeshbio/Amplicon_course/blob/master/krona_qiime.py). The Krona Tools (v. 2.7.1) ${ }^{41}$ program, ktImportText.pl, was used to provide interactive visualization of identified fungi species. Venn analysis to compare the fungal diversity obtained from the different sampling locations was carried out using the program available at http://bioinformatics.psb.ugent.be/webtools/Venn/.

\section{Results}

\section{Taxonomy and diversity}

We detected 55,312 fungal DNA reads representing 127 OTUs and 69,755 bacterial DNA reads representing 706 OTUs (Suppl. Table 1). The Mao Tao rarefaction curves did not reach a plateau in all samples, indicating that the total number of fungal and bacterial taxa may be greater than that detected (Suppl. Figure 1). The Krona charts (Fig. 3) illustrate the changes in the fungal and bacterial assemblages with progression through the three disease stages. The fungal phylum Ascomycota dominated the assemblages in all samples, followed by Basidiomycota, Rozellomycota, Chytridiomycota, Mortierellomycota and Monoblepharomycota. Chalara sp. 1, Alpinaria sp., Helotiaceae sp. 2, Chaetothyriales sp. 1, Ascomycota sp. 1 (all Ascomycota), Rozellomycota sp. and Fungi sp. generally displayed relative abundance $>10 \%$ and were the dominant taxa, followed by 15 taxa characterized as intermediate and 109 as minor (rare) components of the total fungal community. The dominant bacterial phylum was Actinobacteriota, followed by Proteobacteria, Bacteroidota and Cyanobacteria, in rank. The class level taxon Cyanobacteriia sp. (Cyanobacteria) represented the dominant prokaryotic taxa. Seventy taxa were characterized as intermediate and 643 as minor components of the bacterial community.

Fungal and bacterial alpha diversity indices across the samples are given in Table 1. The fungal communities displayed high diversity (Fisher a), richness (Margalef) and dominance (Simpson) indices, which increased progressively from the healthy to the dead moss carpet samples. For the bacterial communities the Fisher (diversity) and Margalef (richness) indices were greatest in the the healthy moss, decreasing in the fairy ring infected moss and partially recovering in the dead moss sample. The Simpson (dominance) index did not differ across all samples.

Table 1

Diversity indices of fungal assemblages detected in the different stages of fairy ring infection of established moss carpet.

\begin{tabular}{|c|c|c|c|c|c|c|c|c|}
\hline Diversity & Healthy & & Fairy ring & & Dead & & Total & \\
\hline & Fungi & Bacteria & Fungi & Bacteria & Fungi & Bacteria & Fungi & Bacteria \\
\hline $\begin{array}{l}\text { Number } \\
\text { of taxa }\end{array}$ & 78 & 636 & 83 & 584 & 80 & 602 & 127 & 716 \\
\hline $\begin{array}{l}\text { Number } \\
\text { of reads }\end{array}$ & $12,321.32$ & $22,864.33$ & $24,404.31$ & $23,364.01$ & $18,585.98$ & $23,527.09$ & $55,311.63$ & $69,755.39$ \\
\hline Fisher a & 20.24 & 121.3 & 22.48 & 108.6 & 27.37 & 112.6 & 30.07 & 111.1 \\
\hline Margalef & 7.61 & 63.26 & 8.05 & 57.96 & 8.91 & 59.71 & 12.45 & 64.11 \\
\hline Simpson & 0.68 & 0.98 & 0.83 & 0.98 & 0.90 & 0.97 & 0.91 & 0.98 \\
\hline
\end{tabular}

The beta diversity of the fungal and bacterial assemblages varied across the different samples (Suppl. Figure 2). Both presenceabsence-based Sorensen and the abundance-related Bray-Curtis similarity indices showed that the fungal assemblages detected in the healthy and fairy ring samples were the most similar, while those of the dead moss were the most different, mainly due the dominance of Basidiomycota taxa. In contrast, the bacterial assemblages detected in the healthy and dead moss carpet samples were the most similar and those present in the fairy ring formed a separate group. 
The fungal and bacterial community composition varied through the different stages of the disease (Suppl. Figure 3). For fungi (Suppl. Figure 3a), 42 taxa occurred in all samples, but each disease stage displayed different composition and 20 taxa occurred only in fairy ring and dead samples. For the bacterial communities (Suppl. Figure 3b) the largest proportion of the taxa (254) were present in all samples. Few taxa were in common between healthy/fairy ring, fairy ring/dead and healthy/dead samples.

Comparison of the dominant and intermediate fungal and bacterial communities identified different patterns of composition at the different stages of the infection (Fig. 4; Suppl. Table 2). Amongst the fungi, Chalara sp. 1, Ascomycota sp. 1, Tetracladium sp. 2 and Fungi sp. dominated the healthy moss carpet and decreased in abundance in the fairy ring infected and dead moss. In contrast, Alpinaria sp., Helotiaceae sp. 2, Helotiales sp. 1 and Rozellomycota sp. increased considerably in relative abundance between the healthy and the infected moss samples, but decreased in the dead moss. Finally, Chaetothyriales sp. 1, Serendipita sp., Agaricomycetes sp., Sebacinales sp., Knufia peltigerae, Ascomycota sp. 2, Mortierella fimbricystis, Lamprospora sp., Melanommataceae sp., Pseudogymnoascus sp. 1 and Platygloeaceae sp. were the most abundant fungi in the dead moss but had low relative abundance in the healthy and infected moss.

The relative abundance of the four bacterial phyla varied across the three infection stages. Actinobacteriota displayed moderate abundance in healthy moss carpet, increasing to dominate the bacterial community in the infected moss, and decreasing in the dead moss. In contrast, Proteobacteria, Bacteroidota and Cyanobacteria displayed moderate abundance in healthy moss, which decreased in the infected moss and increased again in dead moss. Among these prokaryote phyla, Cyanobacteriia sp.

(Cyanobacteria) was the dominant taxon, although only reaching intermediate abundance in the infected moss (3.74\%) and dominance in healthy (12.39\%) and dead moss (13.05\%) samples. Microbacteriaceaesp. (Actinobacteriota) and Chloroflexisp. (Chloroflexi) occurred at intermediate abundance in all moss samples, and were the most abundant taxa in the infected moss samples and least adundant in dead moss. Cyanobacteriia sp. and Haliangium sp. (Myxococcota) were the most abundant taxa detected in dead moss.

\section{Discussion}

\section{Fungal diversity}

Mosses are the dominant flora in Antartica, providing habitat for multiple microbial and invertebrate taxa and communities ${ }^{1,14}$. Endophytic and epiphytic fungi and bacteria are considered to be the dominant microorganisms present in these habitats, known as the bryosphere ${ }^{42,43,44}$.

A range of Antarctic moss species have been documented to be vulnerable to infection by 'fairy ring disease'. In the current study comparing the microbial communities present in healthy, visibly infected (within the ring) and dead moss from the same moss carpet, we detected complex and diverse fungal and bacterial communities using a metabarcoding approach. Overall, the fungal community was richer (3.2 times greater) than that reported recently ${ }^{14}$ in a study using culture methods which detected 40 taxa in eight moss species sampled from different locations in the north-west Antarctic Peninsula region. Among the taxa reported by Rosa et al. ${ }^{14}$, only representatives of the genera Alpinaria, Helotiales, Cladosporium, Cadophora, Pseudogymnoascus, Glarea, Chalara, Ophiocordycipitaceae, Juncaceicola and the species Mortierella fimbricystis and Gyoerffyella entomobryoides were shared with the current study.

In the current study, relative abundance of the fungal taxa Alpinaria sp., Helotiaceae sp. 2, Coleophoma sp., Helotiales sp. 1 , Chytridiomycota sp. 2, Rozellomycota sp. and Fungi sp. increased between healthy and infected moss samples, but was lower in dead moss. The genus Alpinaria (Melanommataceae) includes only a single described species (A. rhododendri) and seems to be common in the subalpine to alpine zone worldwide on twigs or buds of Rhododendron spp. (Ericaceae $)^{45}$. It has recently been reported on mosses affected by fairy ring disease in maritime Antarctica ${ }^{14}$. The family Melanommataceae includes plant pathogenic species such as Gemmamyces picea $e^{46}$ and, according to the FunGuild database ${ }^{47}$, A. rhododendri is considered a problable plant pathogenic and/or wood saprotrophic species.

The genus Coleophoma includes species reported as plant pathogenic, saprophytic or endophytic on different plant species ${ }^{48}$. Plant pathogens in the genus include C. fusiformis on leaves of Rhododendron ${ }^{49}$, C. eucalypti and C. eucalyptorum on Eucalyptus ${ }^{50}, C$. 
gevuinae on Gevuina ${ }^{51}$, C. empetri on Vaccinium ${ }^{52}$ and C. proteae on Protea caffra ${ }^{53}$. Rozellomycota species are common in temperate, sub-Arctic and Antarctic environments ${ }^{18}$. According to Grossart et al. ${ }^{54}$, all known Rozellomycota taxa are obligate pathogens of eukaryotes, including amoebae, fungi and algae. However, there are no reports of Rozellomycota acting as plant pathogens. Chytridiomycota, known as chytrids, primarily includes free-living saprophytic taxa present in aquatic and terrestrial environments. However, some species are reconized as plant pathogens, such as Synchytrium endobioticum that causes potato wart disease ${ }^{55}$.

The taxa Chaetothyriales sp. 1, Serendipita sp., Agaricomycetes sp., Sebacinales sp. and Knufia peltigerae are notable due their increase in abundance in dead relative to healthy moss carpet. They may therefore represent major decomposing taxa in the ecological succession following the death of Antarctic moss carpet. The order Chaetothyriales (Ascomycota) includes species with multiple ecological roles, including soil saprophytes, human and animal opportunistic pathogens and plant epi- and/or endophytes $^{56}$. In addition, some representatives of Chaetothyriales are known to colonize extreme environments characterized by drought, oligotrophic conditions, extreme temperatures and high UV-radiation exposure ${ }^{57}$. Some species are known phytopathogens ${ }^{58}$.

Serendipita is a genus with eight known species ${ }^{38}$, including S. indica, formerly known as Piriformospora indica ${ }^{59}$, an endophytic fungus detected in low-nutrient desert soil in Rajasthan, India ${ }^{60}$, which acts to increase nutrient uptake and utilization in its host $^{61,62}$. Serendipita has been reported as an endophyte of bryophytes ${ }^{63}$. Agaricomycetes is a class of Basidiomycota that includes almost 21,000 described species ${ }^{38}$ whose members play different ecologicals role such as decomposers, pathogens and mutualists in different environments ${ }^{64}$.

The order Sebacinales (Agaricomycetes, Basidiomycota) includes species recognized to show diverse interactions with plants, which range from mutualistic root endophytes (obligate biotrophs, mycorrhizae) to saprophytes ${ }^{59}$. Within the order, members of the family Serendipitaceae have been reported from the Antarctic Peninsula associated with the liverwort Barbilophozia hatcheri and the mosses Chorisodontium aciphyllum and Sanionia uncinata ${ }^{65}$.

The genus Knufa comprises black fungi and has six known species ${ }^{66}$. Knufia peltigerae is a lichenicolous fungus ${ }^{58}$ which, $^{2}$ according to Lawrey $\&$ Diederich ${ }^{67}$, represents an important ecological group that form obligate associations with lichens. The ascomata of K. peltigerae (originally reported as Capronia peltigerae) was first described on thalli of the lichen Peltigera rufescens ${ }^{68,69}$. Peltigera rufescens is a cosmopolitan lichen that occurs on sub-Antarctic South Georgia, the South Orkney Islands and in various locations along the Antarctic Pensinula (both east and west coasts, including James Ross and Alexander Islands) ${ }^{70}$. Possibly analogous to the bleaching effect of fairy rings on mosses, Untereiner et al. ${ }^{69}$ reported the presence of $K$. peltigerae ascomata on decolourized or moribund $P$. rufescens thalli. However, it is unclear if $K$. peltigerae was responsible for the discolouration or represents an opportunistic fungus occurring on aging parts of the lichen thalli. The species has been rarely recorded taxa in Antarctica using culture approaches. de Souza et al..$^{71}$ detected the DNA of $K$. peltigerae in cotton baits deposited in a lake at Hennequin point, King George Island, close to a moss carpet that was under attack from fairy ring disease.

The taxa Serendipita sp. and Agaricomycetes sp. occurred exclusively and were dominant in the dead moss carpet. Serendipita species include root fungal endophytes and arbuscular mycorrhizal fungi (AMF) known as plant growth promoters ${ }^{60}$. Bridge \& Newsham ${ }^{72}$ reported Serendipita-like Sebacinale fungi in soil at Mars Oasis, Alexander Island, in the southern maritime Antarctic. The class Agaricomycetes includes about 21,000 described mushroom-forming species with ecological roles such as decomposers, pathogens and mutualists in different terrestrial and aquatic environments ${ }^{64}$.

Chalara sp. displayed high dominance in the healthy moss carpet, decreasing in dominance in infected moss. The genus includes 103 widespread species with multiple ecological functions ${ }^{38}$. Among Chalara species, $C$. fraxinea (teleomorph: Hymenoscyphus pseudoalbidus) has been reported as an emerging epidemic plant pathogen that has severely affected ash tree stands in Europe since $1990^{73,74}$.

Previous studies have concluded that the causative agent of the fairy ring disease in Antarctica is Psychronectria hyperantarctica, identified using classical morphological techniques from its fruiting body ${ }^{9,13}$. However, despite the potentially high taxonomic 
resolution of the metabarcoding approach, we did not detect sequences of $P$. hyperantarctica in any samples. Rather, our data indicated the presence of several other recognized plant pathogenic fungi, supporting the suggestion of Rosa et al. ${ }^{14}$ that the disease may be caused by multiple fungal infections in parallel. The fungal taxa Alpinaria sp., Helotiaceae sp. 2, Coleophoma sp., Helotiales sp., Rozellomycota sp. and Chytridiomycota sp. 2 showed high levels of dominance in infected moss showing fairy ring symtoms, which deserve further detailed taxonomic characterization and assays in vivo using plant models to confirm whether they are able to cause plant disease symptoms. Robinson et al. ${ }^{6}$ demonstrated that moss vegetation in the Windmill Islands, East Antarctica is changing rapidly in response to a drying climate causing declining viability in some species. It is possible that the incidence of fungal attack, evidenced by the fairy ring disease, might be connected to a decrease in moss health resulting from climatic changes in the Antarctic Peninsula region in recent decades, although no studies have specifically addressed this or directly quantified disease incidence.

\section{Bacterial diversity}

Few studies have addressed the bacterial communities associated with Antarctic mosses. Park et al. ${ }^{75}$ studied endophytic bacteria associated with healthy material of the moss Sanionia uncinata. To our knowledge, no studies have focused on the bacterial diversity present specifically in mosses affected by the fairy ring disease in Antartica. However, the overall dominance of the phyla Actinobacteriota, Proteobacteria, Bacteroidota and Cyanobacteria documented here are consistent with studies such as those of Holland-Moritz et al. ${ }^{76}$ and Wang et al. ${ }^{77}$, which reported that moss-associated bacterial communities were commonly dominated by Proteobacteria and Bacteroidetes. Using molecular phylogenetic techniques to analyse the bacterial diversity associated with aquatic moss pillars in continental Antarctic lakes, Nakai et al. ${ }^{78}$ reported Proteobacteria, Cyanobacteria and Firmicutes as dominant groups. Park et al. ${ }^{75}$ and Câmara et al. ${ }^{79}$ reported highest relative abundances of sequences representing the phylum Actinobacteria in a transplanted $S$. uncinata carpet moss in a study also carried out on Keller Peninsula. Raymond ${ }^{80}$ reported $^{2}$ Actinobacteria (genera Conexibacter, Rhodococcus, Marmoricola, Micromonospora and Streptomyces) and Bacteroidetes (genera Flavobacterium, Segetibacterium, Epilithonimonas and Pedobacter) from Bryum argenteum leaves, further suggesting that they may offer the moss some freezing protection.

The dominance of Microbacteriaceae sp. (Actinobacteriota) in the assemblage of fairy ring affected moss may be notable. Representatives of Actinobacteria are among the most common prokaryotic organisms in Antarctic terrestrial environments ${ }^{81}$. They are also known as prolific producers of bioactive natural products ${ }^{82}$, including some able to suppress plant diseases ${ }^{83}$. Gu et al. ${ }^{84}$ analysed the diversity and composition of fungal and bacterial communities in continuous cropping soil from Chinese chive cultivation, reporting dominance of Actinobacteria in the same samples where potential phytopathogenic fungi were detected. We found a similar high Actinobacteria abundance pattern to that reported by Gu et al. ${ }^{84}$ in fairy ring infected moss, which may suggest that the abundance of Microbacteriaceae sp. is linked with the presence of pathogenic fungi causing the fairy ring symptons.

The presence of members of the phylum Chloroflexi may indicate involvement with organic matter degradation ${ }^{85}$. Suominen et al. ${ }^{86}$ reported Chloroflexi as important agents of decomposition in the Black Sea sulphidic zone. Colatriano et al. ${ }^{87}$ reported that the genomes of Chloroflexi from the Arcic Ocean include several aromatic compound degradation genes.

Cyanobacteriia sp. and Haliangium sp. (Myxococcota) were present in all moss samples, but were the most abundant taxa detected in dead moss. Cyanobacteria are the dominant phototrophs in Antarctic terrestrial and freshwater ecosystems ${ }^{88}$ and represent the greatest accumulation of biomass the benthic habitats of lakes and ponds ${ }^{89}$. Pandey et al. ${ }^{90}$ reported several cyanobacterial taxa in association with mosses sampled in the Schirmacher Oasis, continental Antarctica. The primary habitats of myxobacteria such as Haliangium are rich in organic matter ${ }^{91}$. These bacteria are strictly aerobic and usually live in the surface layers of the soil, but can also be found in decaying plant material ${ }^{92}$. The dominance of these two taxa in dead moss may be due the high concentration of minerals released during the organic decomposition of the moss.

\section{Conclusions}

Previous culture-based and morphological studies have reported fungi to be the causative agent of the 'fairy ring' disease in different Antarctic mosses species. The use of a metabarcoding approach to assess the diversity of microbial communities associated with different stages of the disease in a carpet of the moss $S$. antarctica revealed, based on sequence assignment, a

Page $7 / 15$ 
greater diversity of associated mutualistics, phytopathogens and decomposer fungi than previously recognised, with clear community differences as the disease progressed. In contrast with the fungal community, bacterial diversity decreased in infected relative to healthy moss carpet. We recognise that the metabarcoding approach identifies sequence presence, and does not confirm the viability or functional activity of the species detected. For these reasons, further traditional isolation studies to recover phytopathogenic fungi are necessary to understand if and how fungi may contribute to the disease and, consequently, moss death. In addition, future long-term monitoring of microbial community dynamics associated with moss carpets may provide a novel bioindicator of moss health in Antarctica.

\section{Declarations}

\section{Acknowledgements}

We acknowledge financial support from PROANTAR CNPq (442258/2018-6), INCT Criosfera, FAPEMIG, CAPES, FNDCT and PróReitoria de Pesquisa (PRPq) of the Universidade Federal de Minas Gerais. P. Convey is supported by NERC core funding to the British Antarctic Survey's 'Biodiversity, Evolution and Adaptation' Team. We also thank congresswoman Jô Moraes and the Biological Sciences Institute of the University of Brasilia.

\section{Author contributions}

LHR, LCC and PEASC conceived the study. LCC and LHR performed fungal DNA extraction from mosses samples. LHR, PEASC, LCC, OHBZ, PC, MCS and CAR analyzed the results and wrote the manuscript. All authors read and approved the final manuscript.

\section{Competing interests}

The authors declare no competing interests.

\section{Data Availability Statement}

All raw sequences have been deposited in the NCBI database under the code PRJNA715819.

\section{References}

1. Ochyra, R., Lewis-Smith, R.I., Bednarek-Ochyra, H. The illustrated moss flora of Antarctica. Cambridge University Press, Cambridge, 685p. (2008).

2. Câmara, P.E.A.S. et al. New insights into the species diversity of Bartramia Hedw. (Bryophyta) in Antarctica from a morphomolecular approach. Antarct. Sci.31, 208-215 (2019).

3. Smith, R.I.L. Terrestrial plant biology of the sub-Antarctic and Antarctic, in: Laws, R.M. (ed.) Antarctic Ecology, vol. 1. London, Academic Press, pp. 61-162 (1984).

4. Robinson, S.A. et al. Rapid change in East Antarctic terrestrial vegetation in response to regional drying. Nat. Clim. Chang. 8, 879-884 (2018).

5. Wilson, J.W. Observations on concentric 'fairy rings' in Arctic moss mat. J. Ecol. 39, 407-416 (1951).

6. Racovitza, A. É tude systematique et biologique des champignons bryophiles. Mém. Mus. Natl. hist., Sér. B Bot.10, 1-288 (1959)

7. Hawksworth, D.L. Thyronectria antarctica (Speg.) Seeler var. hyperantarctica D. Hawksw. var. nov. Brit. Antarc. Sur. Bull.32, 5153 (1973).

8. Longton, R.E. The occurrence of radial infection patterns in colonies of polar bryophytes. Brit. Antarct. Sur. Bull. 32, 41-49 (1973)

9. Fenton, J.H.C. Concentric fungal rings in Antarctic moss communities. Trans. Br. Mycol. Soc. 80, 415-420 (1983).

10. Tojo, M. et al.Pythium polare, a new heterothallic oomycete causing brown discolouration of Sanionia uncinata in the Arctic and Antarctic. Fungal Biol. 116, 756-768 (2012). 
11. Pawłowska, J. et al.Psychronectria hyperantarctica, gen. nov., comb. nov., epitypification and phylogenetic position of an Antarctic bryophilous ascomycete. Mycologia 109, 601-607 (2017).

12. Rosa, L.H. et al. Opportunistic fungal assemblages present on fairy rings spread on different moss species in the Antarctic Peninsula. Polar Biol. 43, 587-596 (2020a).

13. Putzke, J., Pereira, A.B. Fungos muscícolas na Ilha Elefante-Antártica. Cad. Pesq. Biol. 24, 155-164 (2012).

14. Rosa, L.H. et al. Fungi in Antarctica: Diversity, Ecology, Effects of Climate Change, and Bioprospection for Bioactive Compounds, in: Rosa, L.H. (ed) Fungi of Antarctica: Diversity, Ecology and Biotechnological Applications, 1st edn. Springer, Switzerland, pp 1-18 (2019).

15. Döbbeler, P. Biodiversity of bryophilous ascomycetes. Biodivers. Conserv.6, 721-738 (1997).

16. Rosa, L.H. et al. DNA metabarcoding uncovers fungal diversity in soils of protected and non-protected areas on Deception Island, Antarctica. Sci. Rep.10, 1-9 (2020b).

17. Rosa, L.H. et al. DNA metabarcoding of fungal diversity in air and snow of Livingston Island, South Shetland Islands, Antarctica. Sci. Rep. 10, 1-11 (2020c).

18. Rosa, L.H. et al. DNA Metabarcoding to Assess the Diversity of Airborne Fungi Present over Keller Peninsula, King George Island, Antarctica. Microb. Ecol. doi: 10.1007/s00248-020-01627-1 (2020d).

19. Chen, S. et al. Validation of the ITS2 region as a novel DNA barcode for identifying medicinal plant species. PloS One5, e8613 (2010).

20. Richardson, R.T. et al. Application of ITS2 metabarcoding to determine the provenance of pollen collected by honey bees in an agroecosystem. Appl. Plant Sci. 3, 1400066. (2015).

21. White, T.J. et al. Amplification and direct sequencing of fungal ribosomal RNA genes for phylogenetics, in: Innis, M.A., Gelfand, D.H., Sninsky, J.J., White, T.J. (eds) PCR Protocols: a guide to methods and applications, 1 st edn. Academic Press, New York, pp 315-322 (1990).

22. Herlemann, D.P. et al. Transitions in bacterial communities along the $2000 \mathrm{~km}$ salinity gradient of the Baltic Sea. ISME J. $\mathbf{5}$, 1571-1579 (2011).

23. Klindworth, A. et al. Evaluation of general $16 \mathrm{~S}$ ribosomal RNA gene PCR primers for classical and next-generation sequencingbased diversity studies. Nucleic Acids Res. 41, e1-e1 (2013).

24. Joshi, N.A., Fass, J.N. Sicle: a sliding-window, adaptive, quality-based trimming tool for FastQ files. (Version 1.33) [Software] https ://githu b.com/najos hi/sickle (2011).

25. Bolyen, E. et al. Reproducible, interactive, scalable and extensible microbiome data science using QIIME 2. Nat. Biotechnol.37, 852-857 (2019).

26. Callahan, B.J. et al. DADA2: high-resolution sample inference from Illumina amplicon data. Nat. Methods13, 581-583 (2016).

27. Bokulich, N.A. et al. Optimizing taxonomic classification of marker-gene amplicon sequences with QIIME 2's q2-featureclassifier plugin. Microbiome6, 90 (2018).

28. Abarenkov, K. UNITE QIIME release for eukaryotes. Version 04.02. 2020. UNITE Community (2020).

29. Bokulich, N.A. et al. Quality-filtering vastly improves diversity estimates from Illumina amplicon sequencing. Nat. methods10, 57-59 (2013).

30. Amir, A. et al. Deblur Rapidly Resolves Single-Nucleotide Community Sequence Patterns. mSystems 2, e00191-16 (2017).

31. Medinger, R. et al. Diversity in a hidden world: potential and limitation of next-generation sequencing for surveys of molecular diversity of eukaryotic microorganisms. Mol. Ecol.19, 32-40 (2010).

32. Weber, A.A., Pawlowski, J. Can abundance of protists be inferred from sequence data: a case study of Foraminifera. PloS One8, e56739 (2013).

33. Giner, C.R. et al. Environmental sequencing provides reasonable estimates of the relative abundance of specific picoeukaryotes. Appl. Environ. Microbiol.82, 4757-4766 (2016).

34. Deiner, K. et al. Environmental DNA metabarcoding: Transforming how we survey animal and plant communities. Mol. Ecol.26, 5872-5895 (2017). 
35. Hering, D. et al. Implementation options for DNA-based identification into ecological status assessment under the European Water Framework Directive. Water Res.138, 192-205 (2018).

36. Kirk, P.M. et al. Dictionary of the Fungi. CAB International, Wallingford (2011).

37. Tedersoo, L. et al. High-level classification of the Fungi and a tool for evolutionary ecological analyses. Fungal Div. 90, 135-159 (2018).

38. de Carvalho C.R. et al. (2019) Fungi associated with plants and lichens of Antarctica, in: Rosa, L.H. (ed) Fungi of Antarctica: Diversity, Ecology and Biotechnological Applications, 1st edn. Springer, Switzerland, pp 165-199 (2019).

39. Hammer, Ø., Harper, D.A.T., Ryan, P.D. PAST: Paleontological Statistics Software Package for Education and Data Analysis. Palaeontol. Electron.4, 1-9 (2001).

40. Ondov, B.D., Bergman, N.H., Phillippy, A.M. Interactive metagenomic visualization in a Web browser. BMC Bioinformat.12, 385 (2011).

41. Möller, C., Dreyfuss, M.M. Microfungi from Antarctic lichens, mosses and vascular plants. Mycologia 88, $922-933$ (1996).

42. Tosi, S., Casado, B., Gerdol, R. Fungi isolated From Antarctic mosses. Polar Biol. 25, 262-268 (2002).

43. de Carvalho, C.R. et al. Cultivable fungi associated with bryosphere of bipolar mosses Polytrichastrum alpinum and Polytrichum juniperinum in King George Island, South Shetland Islands, Maritime Antarctica. Polar Biol. 43, 545-553 (2020).

44. Hashimoto, A. et al.Pseudodidymellaceae fam. nov.: phylogenetic affiliations of mycopappus-like genera in Dothideomycetes. Stud. Mycol. 87, 187-206 (2017).

45. Jaklitsch, W.M., Voglmayr, H. Three former taxa of Cucurbitaria and considerations on Petrakia in the Melanommataceae. Sydowia 69, 81-95 (2017).

46. Nguyen, N.H. et al. FUNGuild: an open annotation tool for parsing fungal community datasets by ecological guild. Fungal Ecol. 20, 241-248 (2016).

47. Crous, P.W., Groenewald, J.Z. They seldom occur alone. Fungal Biol. 120, 1392-1415 (2016).

48. Sutton, B.C. The Coelomycetes. Fungi Imperfecti with Pycnidia, Acervuli and Stromata. Commonwealth Mycological Institute, Kew, Surrey, England, 696p. (1980).

49. Prather, H.M., et al. Species-specific effects of passive warming in an Antarctic moss system. Royal Soc. Open Sci.6,190744 (2019).

50. Yuan, Z.Q. Fungi and associated tree diseases in Melville Island, Northern Territory, Australia. Aust. Syst. Bot.9, 337 e360 (1996).

51. Bianchinotti, M. ., Rajchenberg, M. Coleophoma gevuinae comb. nov., a foliar pathogen on Gevuina avellana (Proteaceae). Sydowia-Horn 56, 1-5 (2004).

52. Polashock, J.J. et al. The North American cranberry fruit rot fungal community: a systematic overview using morphological and phylogenetic affinities. Plant Pathol.58, 1116-1127 (2009).

53. Crous, P.W. et al. Fungal planet description sheets: 107-127. Persoonia28, 138-182 (2012).

54. Grossart, H.P. et al. Discovery of dark matter fungi in aquatic ecosystems demands a reappraisal of the phylogeny and ecology of zoosporic fungi. Fungal Ecol.19, 28-38 (2016).

55. van de Vossenberg, B.T.L.H. et al. Comparative genomics of chytrid fungi reveal insights into the obligate biotrophic and pathogenic lifestyle of Synchytrium endobioticum. Sci. Rep. 9, 8672 (2019).

56. Madrid, H. et al. New and interesting chaetothyrialean fungi from Spain. Mycol. Progr. 15, 1179-1201 (2016).

57. Tsuneda, A., Hambleton, S., Currah, R.S. The anamorph genus Knufia and its phylogenetically allied species in Coniosporium, Sarcinomyces and Phaeococcomyces. Botany 89, 523-536 (2011).

58. Gueidan, C. et al. A reappraisal of orders and families within the subclass Chaetothyriomycetidae(Eurotiomycetes, Ascomycota). Mycol. Prog.13, 1027-1039 (2014).

59. Weiß, M. et al.Sebacinales - one thousand and one interactions with land plants. New Phytol. 211, 20-40 (2016).

60. Verma, A. et al.Piriformospora indica, gen. et sp. nov., a new root colonizing fungus. Mycologia90, 896-903 (1998).

61. Yadav, V. et al. A phosphate transporter from the root endophytic fungus Piriformospora indica plays a role in phosphate transport to the host plant. J. Biol. Chem. 285, 26532-26544 (2010). 
62. Ngwene, B. et al. Phosphate utilization by the fungal root endophyte Piriformospora indica. Plant Soil 405, 231-241 (2016).

63. Varma, A. et al. Piriformospora indica: a novel plant growth-promoting mycorrhizal fungus. Agric. Res. J.1, 117-131 (2012).

64. Hibbett, D.S. et al. 14 Agaricomycetes. In Systematics and evolution (pp. 373-429). Springer, Berlin, Heidelberg (2014).

65. Zhang, T. et al. Molecular analysis of fungal diversity associated with three bryophyte species in the Fildes Region, King George Island, maritime Antarctica. Extremophiles 17, 757-65 (2013).

66. He, F. et al.Knufia aspidiotus sp. nov., a new black yeast from scale insects. Phytotaxa153, 39-50 (2013).

67. Lawrey, J., Diederich, P. Lichenicolous Fungi: Interactions, Evolution, and Biodiversity. Bryologist 106, 80-120 (2003).

68. Fuckel, L. Symbolae Mycologicae. Zweiter Nachtrag. Jb. nass. Ver. Naturk.27, 1-99 (1874).

69. Untereiner, W.A. et al. The phylogenetic position of the lichenicolous ascomycete Capronia peltigerae. Fungal Div. 49, 225-233 (2011).

70. Øvestal, D.O., Smith, R.I.L. Lichens of Antarctica and South Georgia: A Guide to Their Identification and Ecology. Cambridge University Press, Cambridge, 452p. (2001).

71. de Souza, L.M.D. et al. Assessment of fungal diversity present in lakes of Maritime Antarctica using DNA metabarcoding: a temporal microcosm experiment. Extremophiles25, 77-84 (2021).

72. Bridge, P.D., Newsham, K.K. Soil fungal community composition at Mars Oasis, a southern maritime Antarctic site, assessed by PCR amplification and cloning. Fungal Ecol.2, 66-74 (2009).

73. Kowalski, T. Chalara fraxinea sp. nov. associated with dieback of ash (Fraxinus excelsior) in Poland. For. Pathol.36, 264-270 (2006).

74. Husson, C. et al.Chalara fraxinea is an invasive pathogen in France. Eur. J. Plant Pathol.130, 311-324 (2011).

75. Park, M. et al. Endophytic bacterial diversity of an Antarctic moss, Sanionia uncinata. Antarct. Sci. 25, 51 (2013).

76. Holland-Moritz, H. et al. Novel bacterial lineages associated with boreal moss species. Environ. Microbiol.20, 2625-2638 (2018).

77. Wang, S. et al. Moss habitats distinctly affect their associated bacterial community structures as revealed by the highthroughput sequencing method. World J. Microbiol. Biotechnol. 34,58 (2018).

78. Nakai, R. et al. Microflorae of aquatic moss pillars in a freshwater lake, East Antarctica, based on fatty acid and 16S rRNA gene analyses. Polar Biol. 35, 425-433 (2012).

79. Câmara, P.E.A.S. et al. Practical measures to minimize environmental impact associated from Antarctic station construction: the largest moss carpet transplant in Antarctica and impact on its contained cryptic biodiversity. Extremophiles, in review (2021).

80. Raymond, J.A. Dependence on epiphytic bacteria for freezing protection in an Antarctic moss, Bryum argenteum. Environ. Microbiol. Rep. 8, 14-19 (2016).

81. Pearce A. et al.Metagenomic analysis of a southern maritime Antarctic soil. Front. Microbiol. 3, 403 (2012).

82. Liu, X. et al. Systematics-guided bioprospecting for bioactive microbial natural products. Antonie Van Leeuwenhoek 101, 55-66 (2012).

83. Palaniyandi, S.A. et al. Effects of actinobacteria on plant disease suppression and growth promotion. Appl. Microbiol. Biotechnol.97, 9621-9636 (2013).

84. Gu, Y. et al. Study on the diversity of fungal and bacterial communities in continuous cropping fields of chinese chives (Allium tuberosum). BioMed Res. Int. 3589758 (2020).

85. Speirs, L. et al. The Phylogeny, Biodiversity, and Ecology of the Chloroflexi in Activated Sludge. Front. Microbiol. 10, 2015 (2019).

86. Suominen, S. et al. A diverse uncultivated microbial community is responsible for organic matter degradation in the Black Sea sulphidic zone. Environ. Microbiol. (2019). doi: 10.1111/1462-2920.14902

87. Colatriano, D. et al. Genomic evidence for the degradation of terrestrial organic matter by pelagic Arctic Ocean Chloroflexi bacteria. Communi. Biol.1, 90 (2018).

88. Taton, A. et al. Cyanobacterial diversity in natural and artificial microbial mats ofLake Fryxell (McMurdo Dry Valleys, Antarctica): a morphologicaland molecular approach. Appl. Environ. Microbiol. 69, 5157-5169 (2003).

Page $11 / 15$ 
89. Vincent, W.F. Evolutionary origins of Antarctic microbiota: invasion, selection and endemism. Antarc. Sci.12, 374-385 (2000).

90. Pandey, K.D. et al. Cyanobacteria in Antarctica: ecology, physiology and cold adaptation. Cell. Mol. Biol. (Noisy-le-grand)50, 575-584 (2004).

91. Fudou, R. et al.Haliangium ochraceumgen. nov., sp. nov. and Haliangium tepidumsp. nov.: novel moderately halophilic myxobacteria isolated from coastal saline environments. J. Gen. Appl. Microbiol.48, 109-115 (2002).

92. Reichenbach, H. The ecology of the myxobacteria. Environ. Microbiol.1, 15-21 (1999).

\section{Figures}

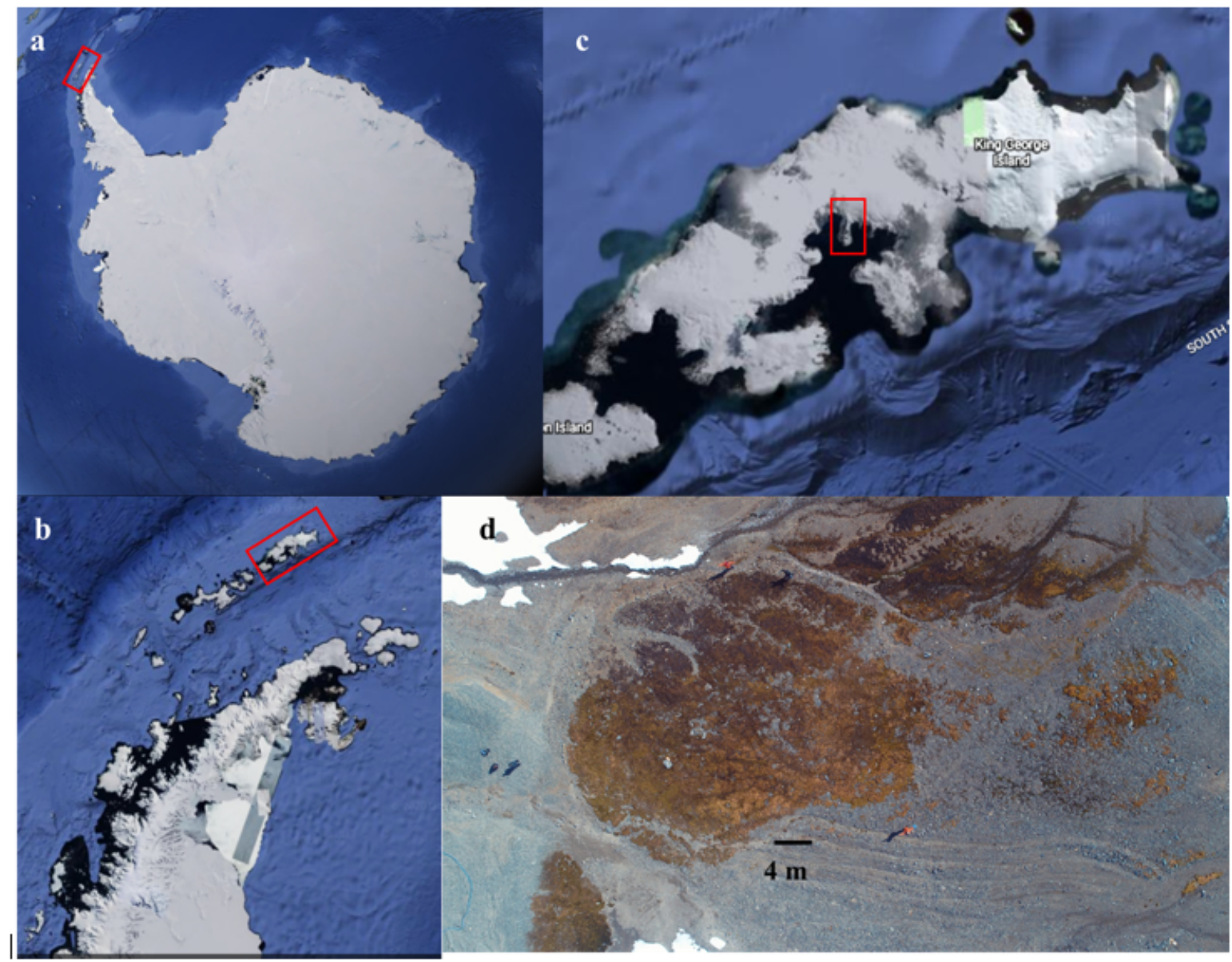

\section{Figure 1}

Satellite images a, b and c (obtained in Google Earth Pro, 2019) indicating where the moss samples were obtained. (a) Antarctic continent with the north-west Antarctic Peninsula and South Shetland Islands inside the red rectangle, (b) Antarctic Peninsula with the South Shetland Islands archipelago inside the red rectangle, (c) King George Island with the Keller Peninsula inside the red rectangle, (d) aerial view of the well established moss carpet (total area $530 \mathrm{~m} 2$ ) from which samples were obtained on the Keller Peninsula, close to the Brazilian Antarctic Station Comandante Ferraz (62 ${ }^{\circ} 5^{\prime} 12.869^{\prime \prime}$ S; 58 $23^{\prime} 42.312^{\prime \prime}$ W). Photo L.H. Rosa. 


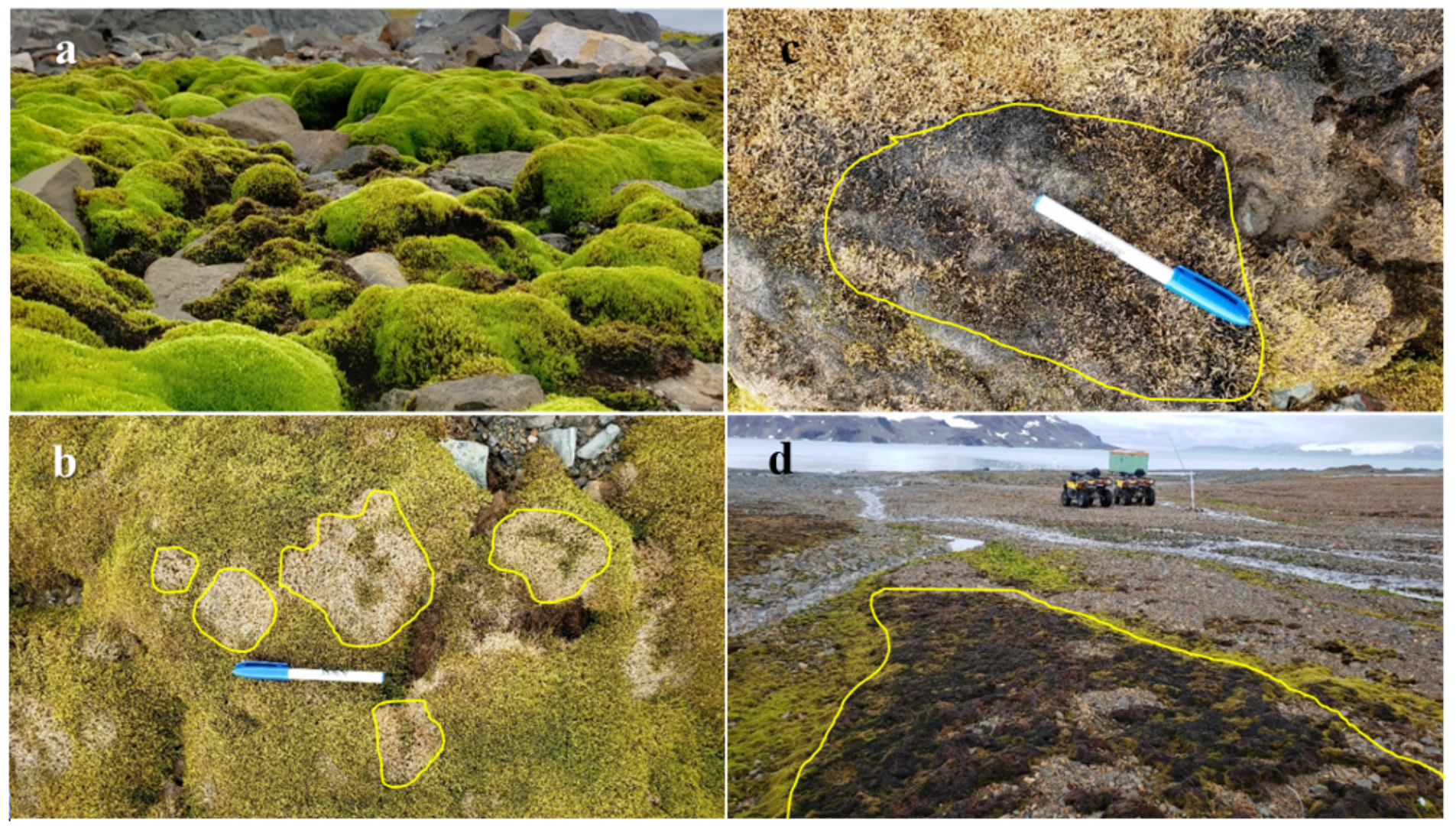

\section{Figure 2}

Different stages of the fairy ring disease. (a) Healthy moss carpet, (b) moss carpet showing fairy rings, (c) dead moss within carpet, (d) a larger area of the moss carpet undergoing decomposition. The yellow lines in b outline the fairy ring and in $c$ and $d$ areas of decomposition. Photos L.H. Rosa. 

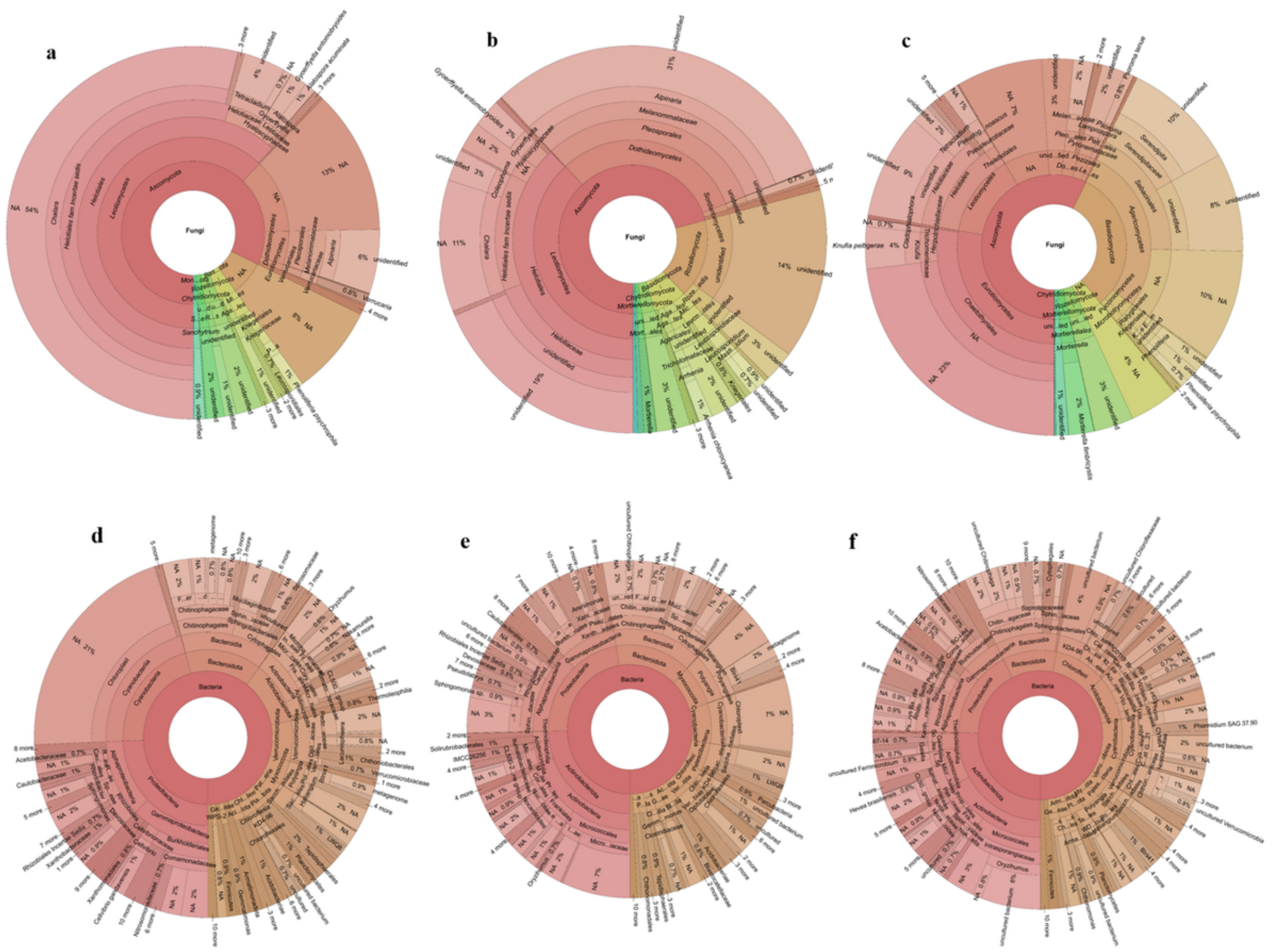

\section{Figure 3}

Krona charts of the different fungal and bacterial assemblages detected. Fungi: (a) healthy moss carpet, (b) moss carpet with fairy ring symptoms and (c) dead moss carpet. Bacteria: (d) healthy moss carpet, (e) moss carpet with fairy ring symptoms and (f) dead moss carpet. 


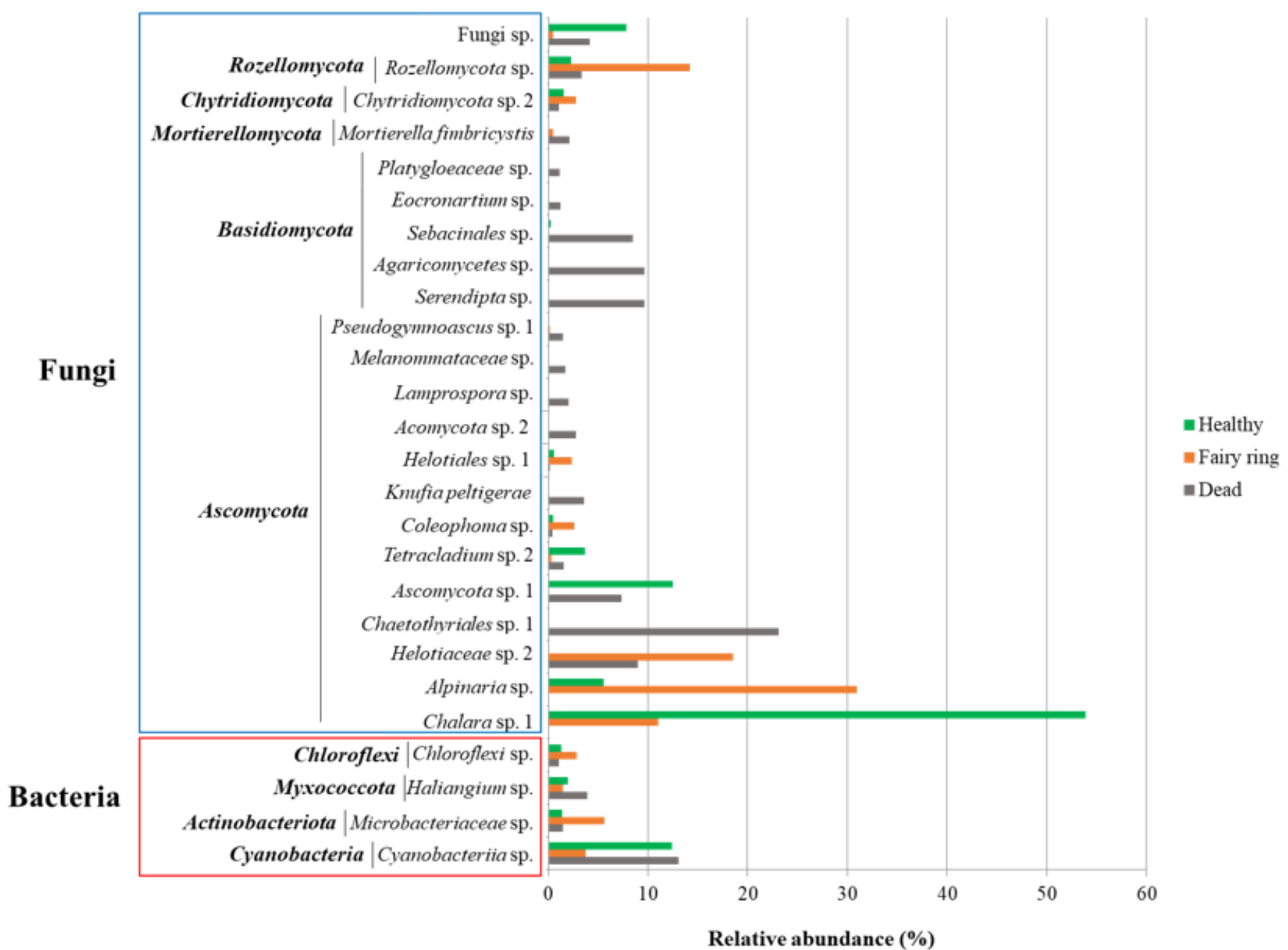

Figure 4

Comparison of the relative abundance fungal and bacterial taxa assemblages in moss samples collected from an established moss carpet on Keller Peninsula, King George Island, South Shetland Islands, at the three stages of infection (healthy, infected fairy ring and dead moss).

\section{Supplementary Files}

This is a list of supplementary files associated with this preprint. Click to download.

- Suppl.Fig.1.docx

- Suppl.Fig.2.docx

- Suppl.Fig.3.docx

- Suppl.Table1.docx

- Suppl.Table2.docx 